\title{
Design, Synthesis, and Biological Evaluation of Dual c-Met/HDAC Inhibitors Bearing 2-Aminopyrimidine Scaffold
}

\author{
Qingwei Zhang ${ }^{1 *}$ Guili Xu ${ }^{1,2}$ Ya Bao ${ }^{1,2}$ Minru Jiao ${ }^{1}$ Jianqi Li $^{1}$ \\ ${ }^{1}$ Novel Technology Center of Pharmaceutical Chemistry, Shanghai \\ Institute of Pharmaceutical Industry, China State Institute of \\ Pharmaceutical Industry, Shanghai, PR China \\ ${ }^{2}$ College of Chemistry and Chemical Engineering, Shanghai \\ University of Engineering Science, Shanghai, PR China \\ Address for correspondence Qingwei Zhang, PhD, Novel Technology, \\ Center of Pharmaceutical Chemistry, Shanghai Institute of \\ Pharmaceutical Industry, 285 Gebaini Road, Shanghai 201203, \\ PR China (e-mail: sipiqingwei@163.com).
}

Pharmaceut Fronts 2020;2:e117.
Retraction Notice
Due to a technical error, this article was published in the wrong issue. You can find the correct version here:

https://www.thieme-connect.com/products/ejournals/abstract/10.1055/s-0040-1722543 (c) 2020. The Author(s).

This is an open access article published by Thieme under the terms of the Creative Commons Attribution License, permitting unrestricted use, distribution, and reproduction so long as the original work is properly cited. (https://creativecommons.org/licenses/by/4.0/)

Georg Thieme Verlag KG, Rüdigerstraße 14, 70469 Stuttgart, Germany 